\title{
Secluded maternity areas for parturient dairy cows offer protection from herd members
}

\author{
Margit Bak Jensen, ${ }^{* 1}$ Mette S. Herskin, ${ }^{1}$ and Maria Vilain Rørvang ${ }^{1,2}$ \\ ${ }^{1}$ Department of Animal Science, Aarhus University, Blichers Allé 20, DK-8830 Tjele, Denmark \\ ${ }^{2}$ Department of Biosystems and Technology, Swedish University of Agricultural Sciences, Sundsvägen 16, 23053 Alnarp, Sweden
}

\begin{abstract}
Use of individual maternity pens for dairy cows is recommended to ensure undisturbed calving and postpartum transfer of colostrum to calves, but management of these pens is a challenge due to difficulty predicting the time of calving. If group-housed cows, however, have the opportunity to calve in a secluded area of a group pen, this may limit disturbance of the dam and her newborn, especially if this area is fitted with a gate preventing other cows from entering. The aims of this study were to assess effects of cows calving inside a secluded area versus cows calving in the group area on maternal behavior and social interaction between dam and herd members during the first postpartum hour, calf's latency to stand, number of calves suckling an alien cow, and the dam's acute response to separation from the calf. This was investigated in pens consisting of a central group area with access to 6 secluded areas with or without a mechanical push gate allowing only 1 cow access at a time. At least 2 wk before expected calving, 60 Danish Holstein multiparous cows were assigned alternately, in groups of 6 , to a group pen with 6 gated secluded areas or a group pen with 6 ungated secluded areas. The effects of treatment (gated, ungated) and calving place chosen within treatment (secluded area, group area) on maternal behavior, interactions with herd members, maternal response to separation, and calf latency to stand were investigated. Irrespective of whether cows calved in a secluded area or not and whether the secluded area was gated or not, cows spent, on average, $39( \pm 7.9)$ min of the first hour after calving licking their calves. When calving in a gated secluded area, the cows interacted less with herd members than when calving in the group area $(0.5,28,18$, and 33
\end{abstract}

Received October 23, 2018.

Accepted February 1, 2019

*Corresponding author: MargitBak.Jensen@anis.au.dk $\mathrm{min} / \mathrm{h}$ for gated/secluded, gated/group, ungated/secluded, and ungated/group areas, respectively), and no calves suckled an alien cow within the first hour after birth. In addition, the longer the calf stayed with the dam, the longer the dam stood with her head out of the pen after removal of the calf. Calf's latency to stand after calving was unaffected by treatment and calving place $($ mean $=39 \mathrm{~min}$; range $=8-243 \mathrm{~min}$ ). The results show that dam and calf can be protected from disturbances when cows calve in a secluded maternity area, especially if the secluded maternity area is fitted with a gate preventing other cows form entering.

Key words: calving, housing, maternal behavior, cowcalf bonding, maternity pens

\section{INTRODUCTION}

Studies on cattle kept outdoors suggest that cows are motivated to maintain visual cover or physical distance to the herd when calving, thereby facilitating maternal bonding without disturbance (reviewed by Rørvang et al., 2018b). When cows calve indoors, use of individual maternity pens protects the dam and calf from disturbances from conspecifics (Edwards, 1982). However, stock people encounter difficulties predicting the time of calving (Lange et al., 2017), constituting a risk that cows are not moved to the individual maternity pen before calving, which in turn may prolong the second stage of calving (Proudfoot et al., 2013). Hence, rather than handling the cow, it may be better to allow her to seek undisturbed conditions based on her natural motivation. In a motivation-based calving facility described by Rørvang et al. (2018a), cows were provided an opportunity to isolate in a secluded area of a group maternity pen, but only approximately $50 \%$ of the cows calved there. The present study used these animals to investigate effects of the chosen calving site (secluded or group area) on selected measures of maternal and neonatal behavior and the social interaction between dam and herd members where secluded areas were either gated, or ungated, using the same experimental set-up and experimental animals as Rørvang et al. (2018a). 
Immediately after calving, the dam licks her calf intensely, and the majority of calves stand within the first hour of birth (Edwards, 1982; Jensen, 2012; Campler et al., 2015). Although the evolutionary significance of maternal licking is likely the stimulation of suckling, in dairy cattle the likelihood of calves suckling within $6 \mathrm{~h}$ of birth was unrelated to maternal licking (Edwards, 1982). When group-housed, $25 \%$ of calves (Illmann and Špinka, 1993) and 33\% of calves (Edwards, 1983) suckled an alien cow, and Edwards (1983) found that the majority of alien cows that had been suckled had not yet calved themselves, but were within $24 \mathrm{~h}$ of calving. Interference from alien cows may therefore result in alien cows nursing the calf, potentially leading to failure of passive transfer of immunity via colostrum. In cattle, the maternal bond is formed within hours after birth (Hudson and Mullord, 1977; Marchant-Forde et al., 2002), and some studies imply that calves of older dams are quicker to stand after calving and interrupt suckling less than calves of first parity dams (Edwards and Broom, 1982). However, it is unknown whether calving in a secluded area affects the formation of the maternal bond. The maternal bond is evident by the dam responding behaviorally; for example, by standing with the head out of the pen from which her calf is removed (Weary and Chua, 2000; Stěhulová et al., 2008; Johnsen et al., 2015).

The aims of the present study were to assess the effects of cows calving inside a secluded area versus cows calving in a group area on maternal behavior, social interaction between dam and herd members during the first postpartum hour, calf latency to stand, number of calves suckling an alien cow, and the dam's acute response to separation from the calf. Our hypotheses were that calving in a gated secluded area would lead to calves standing quicker and fewer calves suckling alien cows, fewer interactions between dam and group members, as well as stronger response from the cows (quantified as time spent standing with the head out of the pen) upon separation from the calves. Additionally, we hypothesized that greater-parity cows would be more maternally responsive when their calf was removed.

\section{MATERIALS AND METHODS}

This study is one in a series of studies focusing on motivation-based calving facilities for dairy cows (Jensen and Rørvang, 2018; Rørvang et al., 2018a). The study took place at the resident herd at the Cattle Research Centre, Department of Animal Science, Aarhus University, Tjele, Denmark, between September 2015 and June 2016, and used the same experimental setup and animals as described in Rørvang et al. (2018a).

\section{Animals, Housing, and Design}

Seventy-eight multiparous Danish Holstein dairy cows were allocated to 1 of 13 groups of 6 cows according to expected calving date. Each group was moved to the experimental pen approximately $14 \mathrm{~d}$ before the expected calving date of the first calving cow within a group and trained to use the gates and the secluded areas as described in Rørvang et al. (2018a). Throughout, pauses between successive calvings within each group were 1 to $2 \mathrm{~d}$, and cows were individually removed from the experiment 5 to $22 \mathrm{~h}$ after calving. After removal of a cow, a pregnant heifer was subsequently added to the group to maintain a constant group size. The groups of 6 cows were alternately assigned to group pens where secluded areas were either gated, allowing only 1 cow access at a time (7 groups), or ungated (i.e., gates to secluded areas were permanently tied open; 6 groups; Figure 1). The group pens comprised a group area $(9 \times$ $9 \mathrm{~m}$ ) with access to 6 secluded areas (each $4.5 \times 3 \mathrm{~m}$ ). Precalving behavior of the involved cows is described in Rørvang et al. (2018a).

The secluded areas were constructed from $1.3-\mathrm{m}$ high pen sides made from tubular metal bars. The $24.5-\mathrm{m}$ sides and a 1.5-m side facing the group pen were fitted with a 1.8-m high, gray, opaque plastic cover. A $1.5-\mathrm{m}$ opening to the group area was left open. The group area and secluded areas were bedded with $15 \mathrm{~cm}$ of sand (Kosand, Dansand, Brædstrup, Denmark; mean grain size $=0.322 \mathrm{~mm}$ ) topped with $15 \mathrm{~cm}$ of uncut barley straw. Each group area was equipped with six 75-cm-wide feed troughs, 2 self-filling water bowls, and 2 wall-mounted brushes, whereas all secluded areas had 1 water bowl and 1 brush. All secluded areas had a gate fitted in the $1.5-\mathrm{m}$ opening between the secluded area and the group area of the group pen, and this gate was either functional or permanently tied open [Figure 1; see also Rørvang et al. (2018a) for a detailed description of the housing design and treatments]. The cows were always able to go back to the group area from a gated secluded area, after which the gate would mechanically unlock allowing another cow entry from the group area. A view from inside a gated and an ungated secluded area is given in Figure 2.

Twice daily (between 0930 and $1200 \mathrm{~h}$ and between 1730 and $1800 \mathrm{~h}$ ), a TMR with a forage-to-concentrate ratio of $80: 20$ on a DM basis was allocated for ad libitum intake in the group area. During these times, fresh straw bedding was added in the group area as well as secluded areas after removal of feces and soiled straw.

Calving was assisted if the calf was not born within 4 $\mathrm{h}$ after the appearance of the amniotic sac. This criteria for intervention was applied to limit disturbing calving cows and their choice of calving site. Suckling was 
assisted within $6 \mathrm{~h}$ of birth unless the calf had been observed to suckle the dam. If calves did not suckle when assisted, the dam was milked and the calf was offered colostrum in a teat bottle for ad libitum intake. If calves ingested less than $3.5 \mathrm{~L}$ of colostrum, they were offered colostrum again within $2 \mathrm{~h}$ of the first colostrum feeding. Calves were only tube fed if they could not suck when assisted or when offered the teat bottle.

\section{Separation of Calves and Dams}

The separation of the calves from their dams always took place from within a secluded area. Hence, in cases where the cow-calf pair was not already positioned in a secluded area, they were moved to one before separation. During separation, the calf was gently removed from the secluded area through a gate to the barn alley (Figure 1). The calf was placed on a trolley and moved to a separate calf barn. The dam was left in the secluded area, but was free to move between secluded areas and the group area until she was removed from the secluded area through the same gate as her calf 12 to 20 min later. The dam was left in the group pen for this short duration of time after removal of the calf to minimize interference with the study of the remaining cows' selection of calving place (Rørvang et al., 2018a).
Separation of the calves from their dams were primarily done in the morning between 0500 and $1100 \mathrm{~h}$.

\section{Behavioral Observations}

During the first hour after calving, the position of the dam in the group pen (secluded area or group area) and the behavior of the dam and any alien cow were recorded continuously (Martin and Bateson, 2007) via video cameras (TVCCD-624, Monacor, Bremen, Germany) by 1 of 2 trained observers (Table 1 ). In this period, the behavior of the calves was recorded as events (incidences counted). The calves' latency to stand was defined as the duration of time from birth until the calf was standing upright for the first time. This variable was recorded throughout the first $5 \mathrm{~h}$ after birth by the same observer that recorded the above described behavior.

At separation, walking, as well as standing with the head out of pen, by the dam was recorded continuously for $12 \mathrm{~min}$, starting the moment when staff separated the calf from the dam (i.e., calf removed from the secluded area; Table 1). The behavior of the calf was only recorded before separation.

Among the 66 cows included in the study of Rørvang et al. (2018a), 6 cows had their calf removed within an

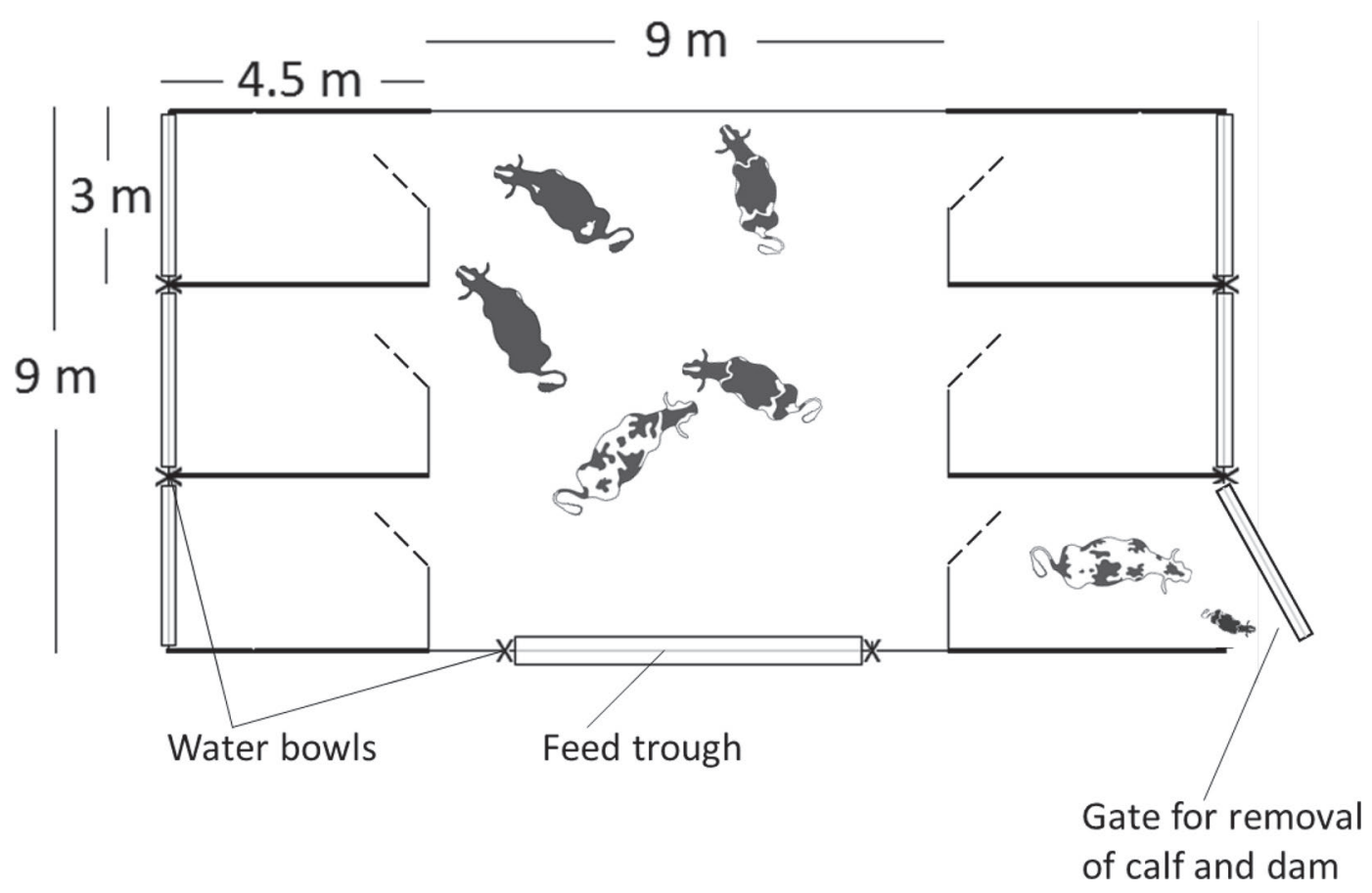

Figure 1. Top view of one of the experimental group pens $(9 \times 18 \mathrm{~m})$, each with 1 group area $(9 \times 9 \mathrm{~m})$ and 6 secluded areas $($ each $3 \times 4.5$ $\mathrm{m})$. Dashed lines indicates the gates, which were either tied open in all secluded areas (ungated) or kept functional in all secluded areas (gated). Cows illustrate the 6 cows in each group. Feed was only provided in the group area, whereas water and brushes were provided in both secluded and group areas. The gate in the secluded area for removal of calf and dam is indicated. 
hour of calving, leaving 60 cows and their calves to be observed during the first hour after calving [32 cows in the gated treatment (17 second and 15 later parity) and 28 cows in the ungated treatment $(6$ second and 22 later parity)]. For the observations of separation of dam and calf, 15 calves were either removed from the group area (i.e., not from within a secluded area) or removed between 1 and $5 \mathrm{~h}$ after calving, resulting in 45 damcalf-pairs being included in the analysis. These calves were removed [median (range)] 9 (5-22) h after calving.
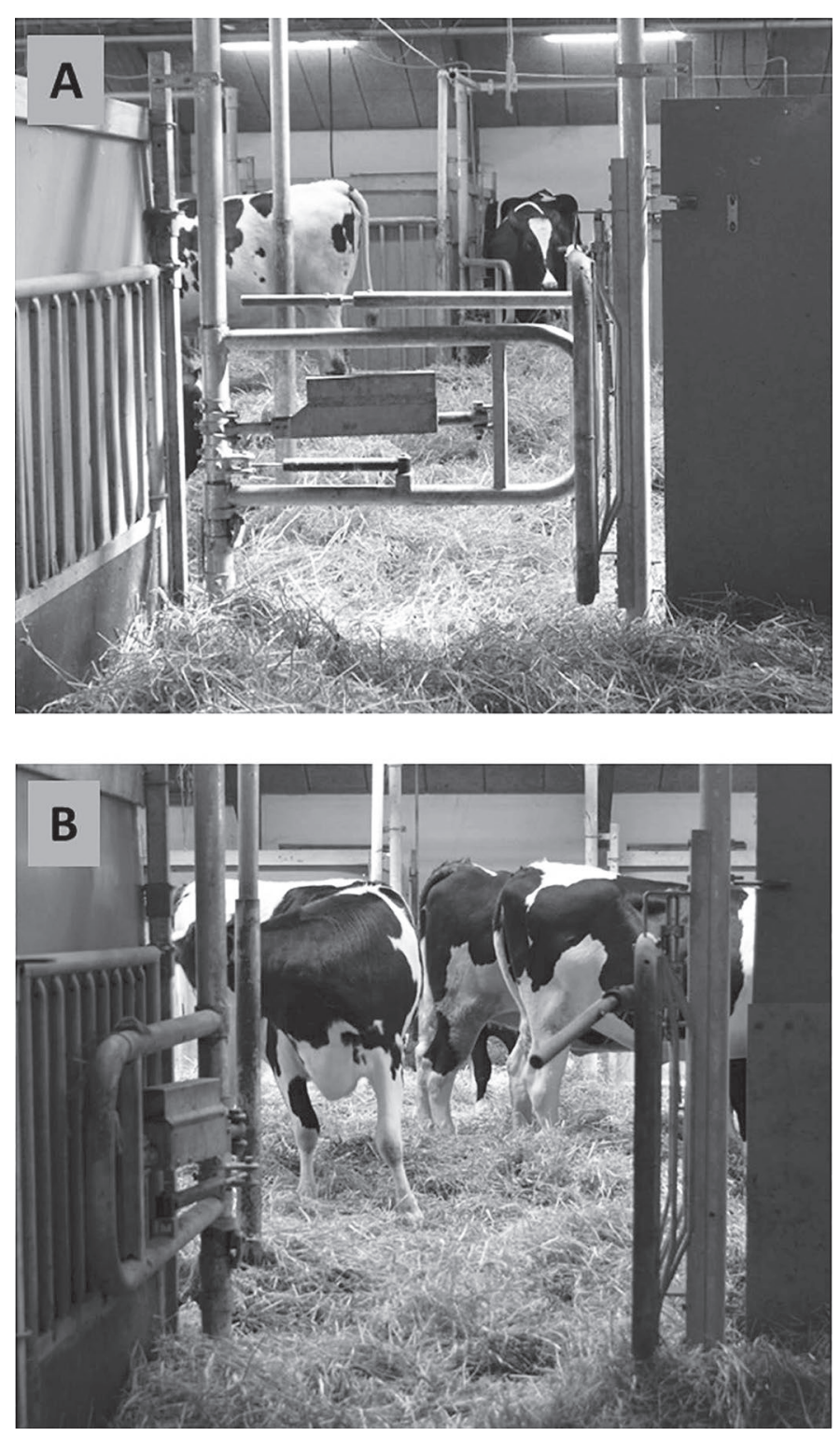

Figure 2. (A) The view from inside a gated secluded area (functional gate) and (B) from inside an ungated secluded area (gate tied permanently open).

\section{Statistical Analysis}

As cows chose where to calve, choice of calving place could not be balanced between secluded areas and the group area. However, to investigate if calving place had an effect on the postpartum behavior, as well as after cow-calf separation, we included calving place as a fixed effect in the below analyses.

Undisturbed Behavior of Dam and Calf. The continuous variables for the dam (duration and frequency of sniffing or licking the calf and duration and frequency of sniffing or licking an alien cow), the alien cows (duration and frequency of contacting the calf), and the calf (latency to stand, number of attempts to stand, and number of standing bouts) were analyzed by a mixed model (SAS ver. 9.4, SAS Institute Inc., Cary, NC), which included the fixed effects of treatment (gated, ungated), calving place (secluded area, group area), interaction between treatment and calving place, as well as parity (second, or later). Random effects included group $(\mathrm{n}=13)$ and observer $(1,2)$. No model reduction was performed. Variables were, if necessary to assume normality, transformed by the square root (frequency of sniffing or licking the calf, frequency of sniffing or licking an alien cow, frequency of an alien cow contacting the calf) or the natural logarithm (duration of sniffing or licking an alien cow, duration of an alien cow contacting the calf) before analysis. For all variables, the residuals were normally distributed, and plotting the predicted values against the residuals confirmed that variance homogeneity could be assumed.

To investigate the effect of selected calving site in pens with gated and ungated secluded areas on number of calves suckling an alien cow within an hour of birth, this variable was analyzed for effects of treatment $x$ calving place by Fisher's exact test (SAS ver. 9.4). The duration of sniffing or licking the calf by the dam and the duration contacting the calf by an alien cow (both untransformed) were correlated using Spearman rank correlations ( $\mathbf{r}_{\mathrm{S}}$; SAS ver. 9.4).

Dam-Calf Separation. Due to low occurrence, the variables head out of secluded area and head out of group area were combined into one variable termed head out of pen. The duration and frequency of head out of pen, walking, and contacts alien cow were analyzed by a mixed model including the fixed effects of treatment (gated, ungated), calving place (secluded area, group area), treatment $\times$ calving place, and parity (second, or later), whereas the duration of time between calving and separation was included as a covariate in the analysis. Group ( $\mathrm{n}=13)$ and observer $(1,2)$ were included as random effects in the model. For all variables, the residuals were normally distributed, and plotting the 
predicted values against the residuals confirmed that variance homogeneity could be assumed.

Results are reported as estimates with test-values and corresponding degrees of freedom. If variables were transformed before analysis, back-transformed estimates are also given. Significance levels of $P<0.05$ are considered significant, whereas $0.05<P<0.10$ are considered tendencies.

\section{RESULTS}

\section{Undisturbed Behavior of Dam and Calf}

Cows spent more than half of the first hour after calving sniffing and licking their calf $[39.3( \pm 7.9)$ $\mathrm{min} / \mathrm{h}$ ], independent of calving place and gate treatment. Significant interactions between treatment and calving place were found for the duration of dam contacting an alien cow, as well as the duration and frequency of an alien cow contacting the calf (Table 2). These behavioral variables were observed significantly less often when dams calved in a gated secluded area. For the frequency of dam contacting an alien cow, the interaction was only a tendency $(P=0.05)$, but the effect of treatment $[0.99( \pm 0.69)$ vs. $2.4( \pm 0.71)$ for gated and ungated, respectively; $\left.F_{1,43}=8.26, P<0.01\right]$ and calving place $[2.4( \pm 0.69)$ vs. $0.92( \pm 0.68)$ for group and secluded area, respectively; $\left.F_{1,43}=20.7, P<0.001\right]$ were both significant. The back-transformed estimates of the frequency of dam contacting an alien cow were 0.98 for cows housed in a group pen with gated secluded areas and 5.8 for cows in a group pen with ungated secluded areas. For cows calving in the group area versus a secluded area of the group pen, the back-transformed values were 5.8 and 0.85 , respectively.

Within the first hour after birth, 11 calves were observed suckling an alien cow; however, none of the calves born inside a gated secluded area (gated/secluded) suckled an alien cow (Fisher's exact test; $P<$ 0.05; Figure 3). The duration of dam sniffing or licking an alien cow and the duration of an alien cow contacting the calf were positively correlated $\left(\mathrm{r}_{\mathrm{S}}=0.57 ; P<\right.$ $0.001)$.

Among cows that calved in group pens where secluded areas were gated, no cows moved between the secluded area and the group area within the first hour after calving. Contrarily, in group pens with ungated secluded areas, $37 \%(7 / 19)$ of the cows that calved in an ungated secluded area moved to the group area, whereas $22 \%(2 / 9)$ of cows that had calved in the group area moved to a secluded area.

The calf's latency to stand was (median and range) $39(8-243)$ min with no effect of treatment or calving place. Calves that were born in the group area had a

Table 1. Description of recorded behaviors of dam, calf, and alien cows

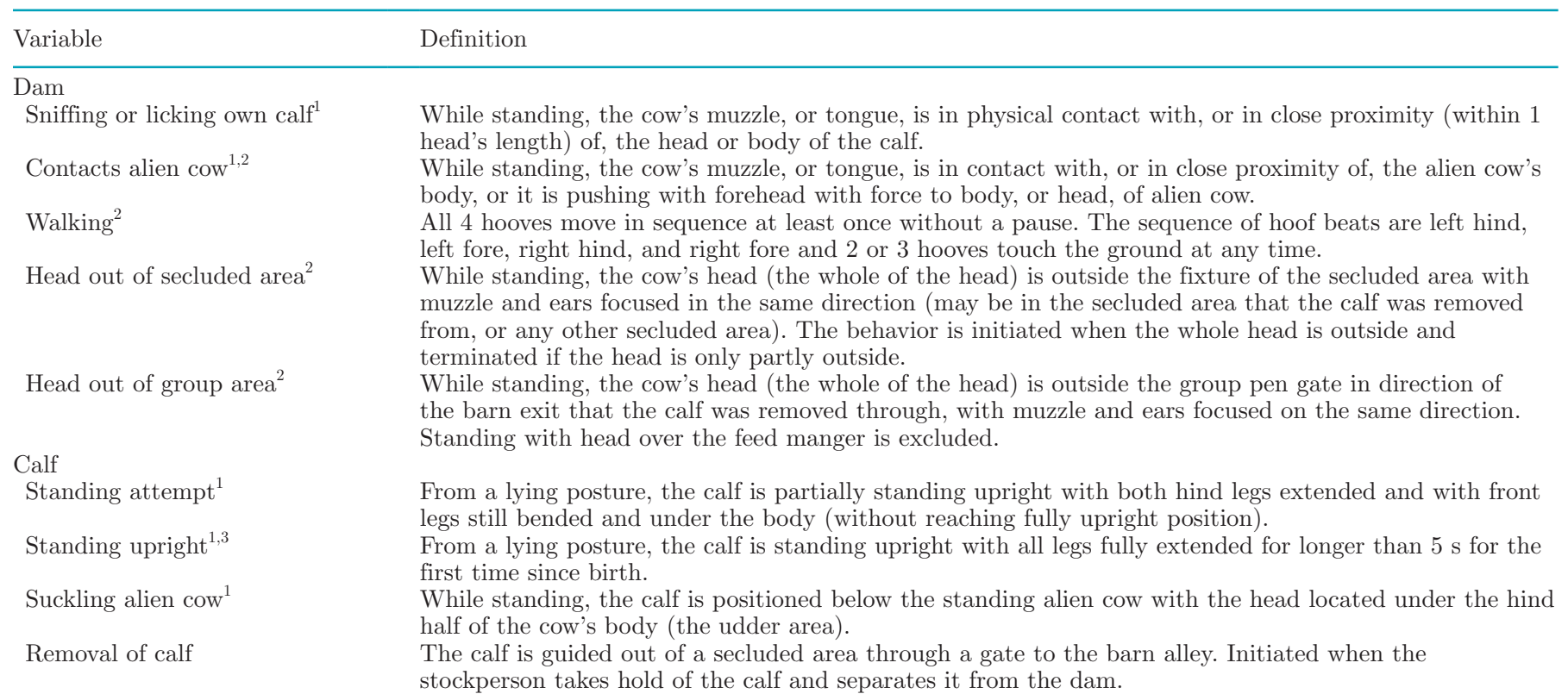

Alien cow

Contacts calf ${ }^{1}$

While standing, any alien cow's muzzle, or tongue, is in contact with, or in close proximity of, the calf's body, or it is pushing with forehead or horn basis with force to body, or head, of calf.

\footnotetext{
${ }^{1}$ Recorded during $1 \mathrm{~h}$ after calving.

${ }^{2}$ Recorded during 12 min after removal of the calf from the pen.

${ }^{3}$ If the calf did not stand within the first hour, the time when the calf stood for the first time was recorded.
} 
SECLUDED MATERNITY AREAS FOR COWS

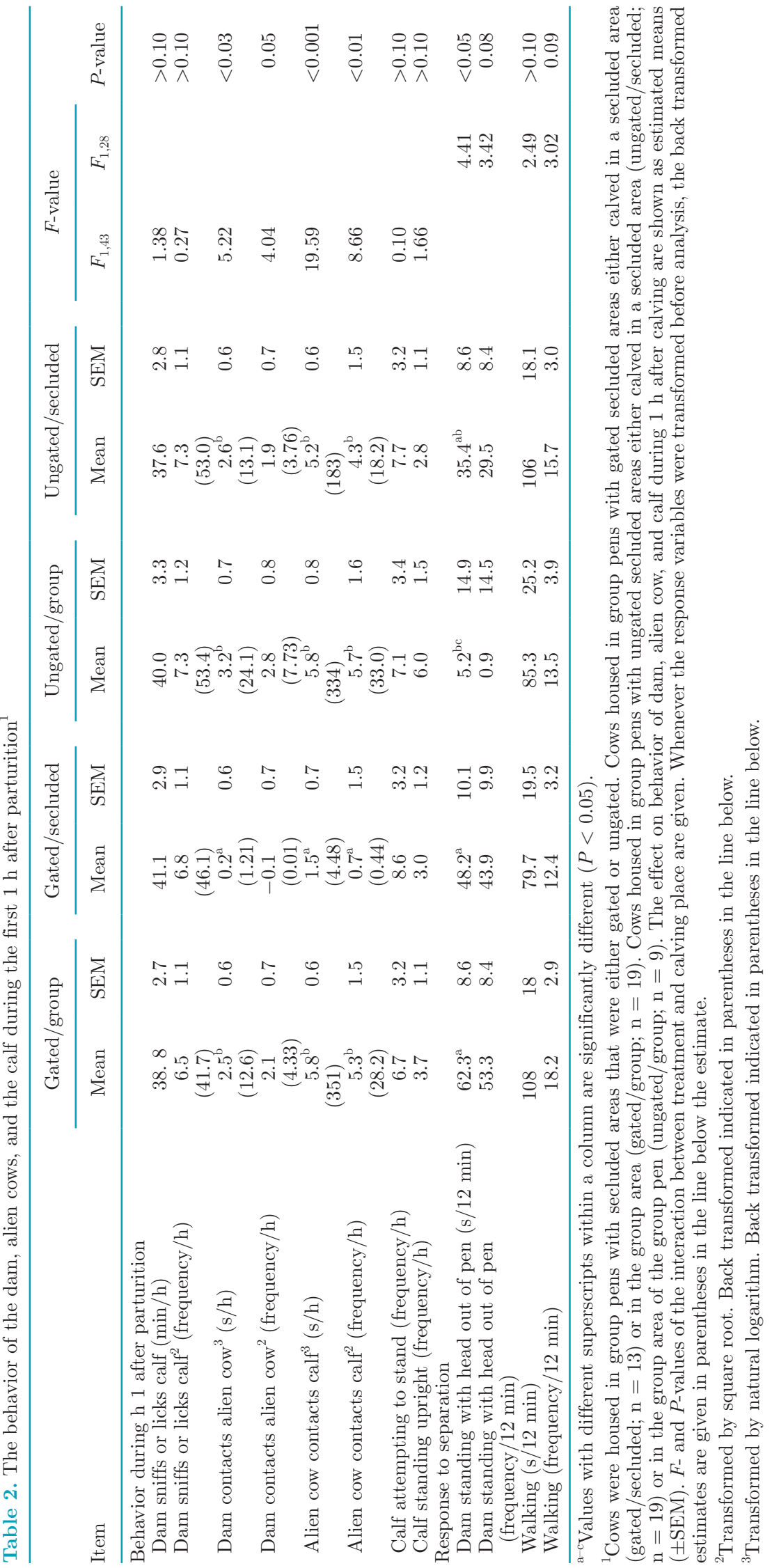




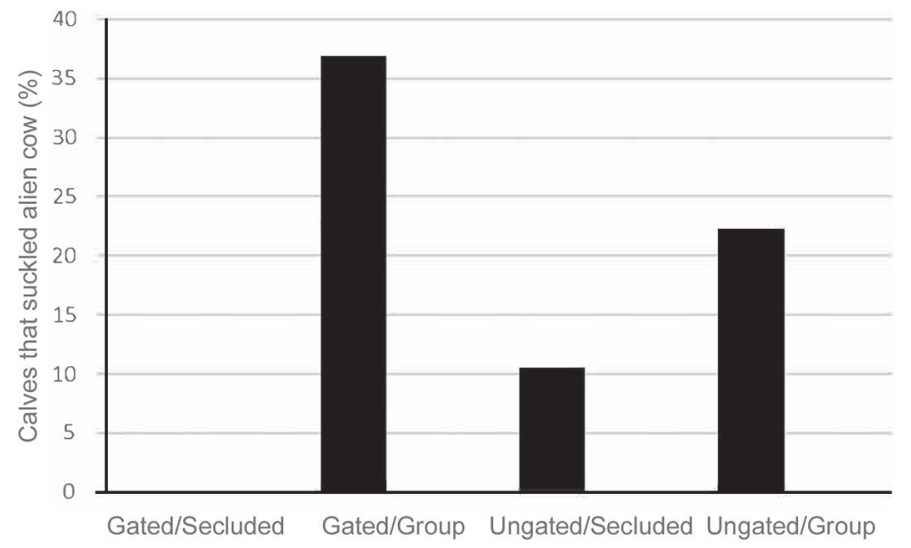

Figure 3. Percentage of calves suckling an alien cow on each of the treatments: gated/secluded (gated secluded area and calf born in the secluded area), gated/group (gated secluded areas and calf born in the group area), ungated/secluded (ungated secluded area and calf born in the secluded area), and ungated/group (ungated secluded area and calf born in the group area).

higher frequency of lying bouts during the first hour after birth [4.8 vs. 2.9 (1.0); $F_{1,43}=3.9 ; P<0.05$ ], whereas no effects were found for the frequency of calf's attempts to stand.

\section{Dam-Calf Separation}

After separation, dams housed in a group pen with gated secluded areas were more often observed standing with their head out of the pen than dams housed in a group pen with ungated secluded areas $[48.6( \pm 6.5)$ vs. $15.2( \pm 8.7)$ frequency $/ 12 \mathrm{~min} ; F_{1,28}=9.22 ; P<$ 0.01]. For the duration of standing with the head out of the pen, dams on the gated treatment spent more time standing with their head out of pen (in either secluded or group area) than dams that had calved in the group area of pens with ungated secluded areas (ungated/group), whereas dams that had given birth in a secluded area of pens with ungated secluded areas (ungated/secluded) were intermediate (Table 2).

Cows of third and older parities had a higher duration $\left[18.2( \pm 8.9)\right.$ vs. $57.4( \pm 6.6) \mathrm{s} / 12 \mathrm{~min} ; F_{1,29}=13.24$; $P<0.01[$ and frequency $[12.6( \pm 8.7)$ vs. $51.2( \pm 6.0)$ frequency $\left./ 12 \mathrm{~min} ; F_{1,29}=13.56 ; P<0.01\right]$ of standing with their head out of the pen during the first $12 \mathrm{~min}$ after separation from the calf than second-parity cows, whereas second-parity cows more frequently contacted alien cows during this period of time $[1.8( \pm 0.46)$ vs. $1.2( \pm 0.42)$ frequency $\left./ 12 \mathrm{~min} ; F_{1,29}=4.59 ; P<0.05\right]$ than later-parity cows. Back-transformed frequency of dam contacting alien cow was 3.24 for second-parity cows and 1.44 for later-parity cows.

The duration of time the calf spent with the dam after calving (covariate in the analysis) was related to the duration of time the dam spent with her head out of the pen following removal of her calf [regression coefficient $\left.0.013( \pm 0.005) ; F_{1,28}=6.76 ; P<0.05\right]$.

\section{DISCUSSION}

This study compared postpartum maternal and neonatal behavior, interactions with herd members, and maternal response to separation in group-housed dairy cows provided with gated or ungated secluded areas. Effects of chosen calving site (i.e., cows calving in either a secluded area or in the group area) were also investigated.

Dams giving birth in a gated secluded area stayed with their calf for the first hour after calving. These calves received minimal attention from alien cows and dams interacted very little with alien cows. Thus, by preventing alien cows from entering the secluded area, the mechanical push-gate effectively protected dam and calf from disturbances. Alien cows are known to direct attention to newborn calves, especially in the hours before they give birth themselves (Edwards, 1983; Illman and Śpinka, 1993). This may explain the finding that newly calved beef cows keep a longer distance to pregnant cows than to dams with calves (Finger et al., 2014) and, in general, spend limited time close to other cows (Swain et al., 2015). In the present study, the duration of time alien cows spent contacting calves correlated positively with the duration of time dams spent contacting alien cows. The motivation underlying the dams' interaction with alien cows may be to prevent alien cows from interacting with their newborn calf; however, based on these results, we cannot separate cause and effect.

By preventing alien cows from entering the secluded area, the gate prevented alien cows from nursing the calf. Calves suckling an alien cow were primarily born in the group area, indicating that some protection from alien cows interfering with the calf was provided by the secluded area, even if the area was ungated. No differences between treatments were seen regarding the calves' latency to stand or the calves' frequency of attempts to stand, but the higher frequency of lying bouts observed among calves that were born in the group area may illustrate that these calves more often lost their balance, possibly due to interactions from an alien cow, or the dam being agitated by alien cows' interference. However, this requires further study.

Irrespective of where the calf was born, separation of calf and dam took place in a secluded area. Standing with the head out of the pen, moving within the pen, and vocalizations are known responses of cows to separation from the calf, and earlier studies have found a stronger response the more days the dam and calf have 
spent together (Flower and Weary, 2001; Stěhulová et al., 2008). No measure of vocalization was included in the present study. However, the finding that dams spent more time with the head out of the pen the longer they had spent with the calf is in accordance with previous studies. For instance, dams also showed a stronger response after $24 \mathrm{~h}$ than after $6 \mathrm{~h}$ together with the calf (Weary and Chua, 2000).

The time spent standing with the head out of the pen was comparable for dams housed in pens with gated secluded areas (irrespective of whether they had calved in the secluded area or not) and dams that calved in an ungated secluded area. The lowest response was found in dams that had calved in the group area of pens with ungated secluded areas. Thus, even if calving in a gated secluded area had the largest effect, having access to a gated secluded area, or having calved in an ungated secluded area, apparently resulted in a stronger bond between the dam and her calf than having calved in the group area of pens with ungated secluded areas. Hence, access to a gated, secluded area during the hours after calving, or having calved in an ungated, secluded area, may therefore facilitate bonding between dam and calf. In one of our earlier studies allowing cows to calve in secluded areas without gates, some dam-calf pairs moved into a secluded area during the first hours after calving in the group area (Jensen and Rørvang, 2018), which may support this suggestion. It is, however, possible that newborn calves actively seek a hiding place. In the present study, we only recorded behavior during the first hour after calving, which is characterized by the cow licking the calf (Edwards and Broom, 1982; Jensen, 2012); at this stage, the position of the calf is likely selected by the cow, although the role of the dams in calves' selection of locations to lie out during the first few days of life is unknown (Rørvang et al., 2018b).

All cows spent a substantial duration of time licking their calf, which illustrates that maternal motivation is high irrespective of treatment and calving place. It could be argued that, because cow and calf in current production systems are separated rather early after calving, the separation might as well be immediately after birth, thereby not allowing any postcalving bonding. However, dam and calf are likely experiencing positive affective states while performing and receiving maternal and neonatal behavior. In addition, exploring opportunities to rear calves with their dam is receiving increasing attention (e.g., Johnsen et al., 2016), and for such rearing systems to be feasible it is essential that a strong maternal bond is formed within the first days of calving. Thus, knowledge of the effect of calving environment on maternal bonding is important. Further research is needed to fully understand the benefits of early dam-calf contact in terms of animal welfare.
Not only the birth place, but also the parity of the dams affected their behavioral response to separation from their calf. Third- and later-parity cows stood more with their head out of the pen after the calf was removed, and these cows also spent less time interacting with alien cows after separation than second-parity cows. The finding that older cows responded more to removal of their calf may suggest a stronger maternal bond in older cows, which may be due to a higher maternal responsiveness in these cows. For instance, Edwards and Broom (1982) found that older cows licked their calves more, indicating a high maternal motivation. However, a stronger maternal bond may also be due to these cows being able to successfully isolate and undisturbed bond to their calf. Why third- and later-parity cows spent less time interacting with alien cows after separation is less obvious, but second-parity cows may have sought more social support from herd members (Rault, 2012) to mitigate the stress of having had their calf removed.

\section{CONCLUSIONS}

In this study of maternal and neonatal bovine behavior, dam and calf were protected from disturbances from herd members when calving took place in a secluded maternity area, especially if the secluded area was fitted with a gate preventing other cows from entering. Such features of the environment resulted in less interactions with herd members, less calves suckling an alien cow, and a stronger acute maternal response to separation. The results illustrate the benefits of protecting the dam and newborn from disturbances when they are kept together for some time after parturition.

\section{ACKNOWLEDGMENTS}

The authors thank Jyden Bur A/S, Vemb, Denmark, for producing and fitting the secluded areas and gates. A special thanks to Anouk van Spronsen (Wageningen University, Wageningen, the Netherlands) and John Misa Obidah (Aarhus University, Aarhus, Denmark) for conducting the behavioral observations. The study was funded by the Green Development and Demonstration Programme of the Danish Ministry of Food, Agriculture and Fisheries, Copenhagen, Denmark.

\section{REFERENCES}

Campler, M., L. Munksgaard, and M. B. Jensen. 2015. The effect of housing on calving behavior and calf vitality in Holstein and Jersey dairy cows. J. Dairy Sci. 98:1797-1804.

Edwards, S. A. 1982. Factors affecting the time to first suckling in dairy calves. Anim. Prod. 34:339-346. 
Edwards, S. A. 1983. The behavior of dairy cows and their newborn calves in individual or group housing. Appl. Anim. Behav. Sci. 10:191-198.

Edwards, S. A., and D. M. Broom. 1982. Behavioral interactions of dairy cows with their Newborn calves and the effects of parity. Anim. Behav. 30:525-535.

Finger, A., K. P. Patison, B. M. Heath, and D. L. Swain. 2014. Changes in the group associations of free-ranging beef cows at calving. Anim. Prod. Sci. 54:270-276.

Flower, F. C., and D. M. Weary. 2001. Effects of early separation on the dairy cow and calf: 2. Separation at 1 day and 2 weeks after birth. Appl. Anim. Behav. Sci. 70:275-284.

Hudson, S. J., and M. M. Mullord. 1977. Investigations of maternal bonding in dairy cattle. Appl. Anim. Ethol. 3:271-276.

Illmann, G., and M. Špinka. 1993. Maternal behavior of dairy heifers and sucking of their newborn calves in group housing. Appl. Anim. Behav. Sci. 36:91-98.

Jensen, M. B. 2012. Behavior around the time of calving in dairy cows. Appl. Anim. Behav. Sci. 139:195-202.

Jensen, M. B., and M. V. Rørvang. 2018. The degree of visual cover and location of birth fluids affect dairy cows' choice of calving site. J. Dairy Sci. 101:9483-9492.

Johnsen, J., K. A. Zipp, T. Kälber, A. M. de Passillé, U. Knierim, K. Barth, and C. M. Mejdell. 2016. Is rearing calves with the dam a feasible option for dairy farms?-Current and future research. Appl. Anim. Behav. Sci. 181:1-11.

Johnsen, J. F., K. Ellingsen, A. M. Grøndahl, K. E. Bøe, L. Lidfors, and C. M. Mejdell. 2015. The effect of physical contact between dairy cows and calves during separation on their post-separation behavioural response. Appl. Anim. Behav. Sci. 166:11-19.

Lange, K., C. Fischer-Tenhagen, and W. Heuwieser. 2017. Predicting stage 2 of calving in Holstein-Friesian heifers. J. Dairy Sci. 100:4847-4856.
Marchant-Forde, J. N., R. M. Marchant-Forde, and D. M. Weary. 2002. Responses of dairy cows and calves to each other's vocalisations after early separation. Appl. Anim. Behav. Sci. 78:19-28.

Martin, P., and P. Bateson. 2007. Measuring Behavior: An Introductory Guide. 3rd ed. King's College, Cambridge University Press, Cambridge, UK.

Proudfoot, K. L., M. B. Jensen, P. M. Heegaard, and M. A. G. von Keyserlingk. 2013. Effect of moving dairy cows at different stages of labor on behavior during parturition. J. Dairy Sci. 96:1638-1646.

Rault, J.-L. 2012. Friends with benefits: Social support and its relevance for farm animal welfare. Appl. Anim. Behav. Sci. 136:1-14

Rørvang, M. V., M. S. Herskin, and M. B. Jensen. 2018a. The motivation-based calving facility: Social and cognitive factors influence isolation seeking behavior of Holstein dairy cows at calving. PLoS One 13:e0191128.

Rørvang, M. V., B. L. Nielsen, M. S. Herskin, and M. B. Jensen. 2018b. Pre-partum maternal behavior of domesticated cattle: A comparison with managed, feral, and wild ungulates. Front. Vet. Sci. 5:45.

Stěhulová, I., L. Lidfors, and M. Špinka. 2008. Response of dairy cows and calves to early separation: Effect of calf age and visual and auditory contact after separation. Appl. Anim. Behav. Sci. 110:144-165.

Swain, D. L., K. P. Patison, B. M. Heath, G. J. Bishop-Hurley, and A. Finger. 2015. Pregnant cattle associations and links to maternal reciprocity. Appl. Anim. Behav. Sci. 168:10-17.

Weary, D. M., and B. Chua. 2000. Effects of early separation on the dairy cow and calf: 1 . Separation at $6 \mathrm{~h}, 1$ day and 4 days after birth. Appl. Anim. Behav. Sci. 69:177-188. 